\title{
Synthesis and antibacterial activity of novel myricetin derivatives containing sulfonylpiperazine
}

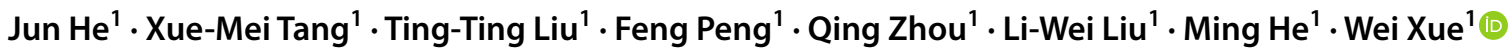

Received: 10 June 2020 / Accepted: 15 September 2020 / Published online: 23 September 2020

(c) The Author(s) 2020

\begin{abstract}
Myricetin derivatives containing sulfonylpiperazine were synthesized and their structures were confirmed by NMR and HRMS. The antibacterial activity results indicated that some compounds showed good antibacterial activity against Xanthomonas oryzaepv. oryzae (Xoo), Xanthomonas axonopodispv. citri (Xac) and Ralstonia solanacearum (Rs). Among them, compounds $\mathbf{4 m}$ and $\mathbf{4 p}$ revealed excellent antibacterial activities against Rs with a concentration for $50 \%$ of maximal effect $\left(\mathrm{EC}_{50}\right)$ value of 4 and $4 \mu \mathrm{g} / \mathrm{mL}$, which were better than the control drugs bismerthiazol $(13 \mu \mathrm{g} / \mathrm{mL})$ and thiodiazole-copper $(185 \mu \mathrm{g} / \mathrm{mL})$. As observed using scanning electron microscope (SEM), these compounds act by causing folding and deformation of the bacterial surface, resulting in incomplete bacterial structure, so as to achieve the goal of bacteriostasis. The myricetin derivatives synthesized are expected to guide the research direction of new antibacterial agents.
\end{abstract}

Keywords Myricetin derivative - Sulfonylpiperazine - Antibacterial activity $\cdot$ Concentration for $50 \%$ of maximal effect . Scanning electron microscope

\section{Introduction}

Plant diseases have always been a headache in agricultural production. The plant bacterial diseases are extremely difficult to control in agricultural production, such as rice bacterial blight, tobacco bacterial wilt, citrus canker and so on (Zou et al. 2011; Li et al. 2017). Since the earliest fungicide bordeaux liquid, a lot of agricultural fungicides have been developed successively. With the development of chemistry, new types of nano-antibacterial agents have also come into the sight of chemists (Khatoon et al. 2017, 2018). Until today, there have been many commercial antibacterial agents with good activity, such as bismerthiazol and thiodiazole-copper etc. However, with the increase in the

Electronic supplementary material The online version of this article (https://doi.org/10.1007/s11696-020-01363-3) contains supplementary material, which is available to authorized users.

\section{Wei Xue}

wxue@gzu.edu.cn

1 State Key Laboratory Breeding Base of Green Pesticide and Agricultural Bioengineering, Key Laboratory of Green Pesticide and Agricultural Bioengineering, Ministry of Education, Guizhou University, Huaxi District, Guiyang 550025, China use of traditional fungicides, the resistance of plant bacteria to them has gradually increases (Yan et al. 2016; Jiang et al. $2020 \mathrm{a}, \mathrm{b}$ ). Therefore, the development of new antibacterial agents is of great significance.

Flavonoids are widely existed in plants in nature, and belong to the secondary metabolites of plants (Manthey and Guthrie 2002). It plays an important role in plant growth, development, flowering, fruiting, antibacterial and disease prevention. Moreover, many studies in recent years have shown that flavonoid-based scaffolds as multi-targetdirected ligands (MTDLs) have shown an important role in the treatment of Alzheimer's disease (Jalili-Baleh et al. 2018). Therefore flavonoids have become a research hotspot in the pharmaceutical and pesticide industries due to their extensive biological activities. Myricetin is a common plant-derived flavonol derived from fruits, vegetables, berries, nuts, tea, etc. (Zhang et al. 2020). Research over the years has shown that myricetin has a wide range of biological activities. Such as antibacterial (Mo et al. 2020), anticancer (Sun et al. 2012), anti-inflammatory (Wang et al. 2010), antiviral (Yu et al. 2012) and antioxidant activities (Guitard et al. 2016). Studies have found that myricetin has the least cytotoxicity to TZM-bl, HeLa, PBMC and H9 cells at a concentration of $100 \mu \mathrm{M}$, with cell viability above $85 \%$, which is better than quercetin and pinocembrin (Pasetto et al. 
2014). Piperazine is an important intermediate in medicine, pesticide and dye. Due to the special chemical structure of piperazine. Piperazine and its series of compounds are important products connecting the chemical industry and the pharmaceutical industry (Suleman et al. 2020), widely used in medicine (Alina et al. 2020), pesticides (Peng and Wang 2018) and other fields. As a kind of pharmacophore group with extensive biological activities in antibacterial (Nadia and Mona 2020), weeding (Chen et al. 2018), anticancer (Štěpánková et al. 2020), antioxidant (Soliman et al. 2020) etc., sulfonamide group has shown excellent activity and great value in the field of medicine and pesticides. Therefore, the structure of sulfonylpiperazine is often used in new drug design and development (Xu et al. 2015).

As a flavonoid with good biological activity, the application of myricetin derivatives have become more and more extensively. For example, some of the myricetin derivatives containing acylhydrazone showed excellent anticancer activity (Xue et al. 2015). Meanwile, some myricetin derivatives containing piperazine amide also showed good anticancer activity (Ruan et al. 2018a, b). And there were also reported some agricultural antibacterial activities of myricetin derivatives (Li et al. 2019; Chen et al. 2019; Jiang et al. 2020a, b). At the cellular level, chalcone containing myricetin can be influenced by inhibiting the differentiation of Gaoyou duck embryonic osteoclasts in vitro (Fu et al. 2019). Tobacco mosaic virus has a great harm to plant growth and development. Some of the myricetin derivatives containing oxadiazole (Zhang et al. 2019) or ferulic acid (Tang et al. 2020) showed good anti-TMV activity.

In summary, we hope to develop a fast and efficient method for constructing the partial skeleton of piperazine and sulfonamides structure with the lead of myricetin by consulting a large number of literatures and combining our previous work of research group, so as to synthesize the new myricetin derivatives containing both piperazine and sulfonyl structure (Fig. 1), and investigated their antibacterial efficacy against Xoo, Xac and Rs in vitro. The antibacterial mechanism of compounds $\mathbf{4}$ were preliminarily studied by SEM. Compared with the previous work of research group, the inhibitory activity of this series of compounds 4 on Rs has been greatly improved. This article attempts to optimize the superposition of these active fragments to find drugs with high antibacterial activity, and provide a reliable research direction for the screening of new antibacterial drugs.

\section{Experimental}

\section{Materials}

piperazine and arylsulfonyl chloride were obtained from Shanghai Titanchem Co., Ltd., and all other reagents were analytical grade. A Bruker Ascend 400 NMR spectrometer (Bruker Optics, Switzerland) was used to record the ${ }^{1} \mathrm{H},{ }^{13} \mathrm{C}$ and ${ }^{19} \mathrm{~F}$ nuclear magnetic resonance (NMR), with tetramethylsilane (TMS) as the internal standard, and $\mathrm{CDCl}_{3}$ as solvent. The melting point tests were conducted in an XT-4 binocular microscope (Beijing Tech Instrument Co., Ltd.). A WFH-203B with three UV analyzer (Shanghai Jingke Industrial Co., Ltd.) was used for thin-layer chromatography (TLC). Deionizing water purifier (Hokee). Vertical High-Pressure Steam Sterilization Pot (Shanghai ShenAn Medical instrument Factory). Multiskan FC (Thermo Fisher Scientific (Shanghai) Co., Ltd.).

\section{Chemicals}

\section{General procedure for preparing the intermediates 1,2 and 3}

As shown in Scheme 1, intermediate $\mathbf{1}$ and $\mathbf{2}$ were prepared via the reported methods (Chen et al. 2019). Myricetrin $(1 \mathrm{mmol})$ and methyl iodide $(15 \mathrm{mmol})$ were stirred $43{ }^{\circ} \mathrm{C}$ for $48 \mathrm{~h}$, and then suction filtration and the filter was extracted with $\mathrm{CH}_{2} \mathrm{Cl}_{2}$, most of the solvent in the filtrate was removed by spin evaporation and hydrochloric acid

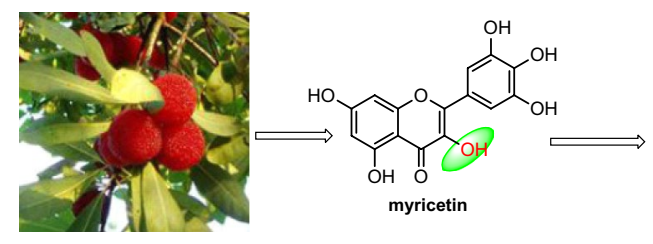

Fig. 1 Design route of the target compounds $4 \mathbf{a}-\mathbf{4 y}$

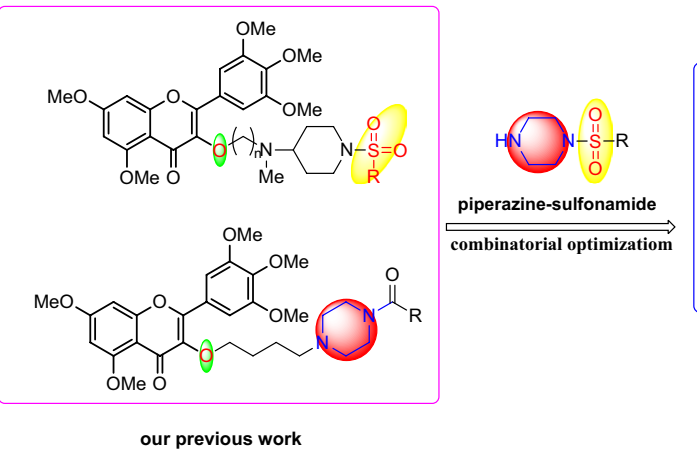




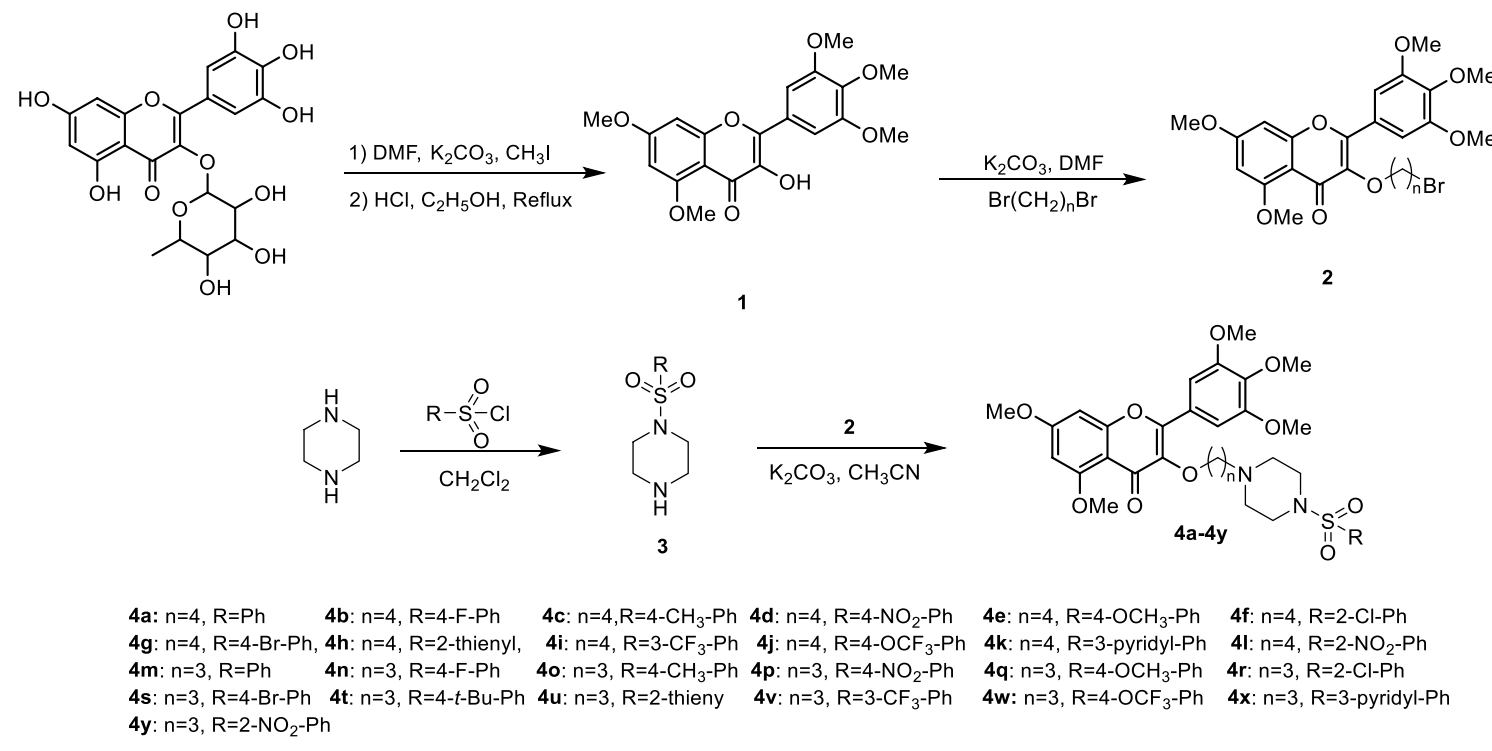

Scheme 1 Synthetic route of the target compounds $\mathbf{4 a - 4 y}$

$(10 \mathrm{~mL})$ was added under reflux in the ethanol to obtain the intermediate $\mathbf{1}$. Finally, the intermediate $\mathbf{1}(10 \mathrm{mmol})$ was stirred in DMF at room temperature for $1 \mathrm{~h}$ and dibromoalkane $(30 \mathrm{mmol})$ was added; this reaction was allowed to continue for $12 \mathrm{~h}$ and pour into water to obtain the intermediate $\mathbf{2}$. And the intermediate $\mathbf{3}$ was prepared by known methods (Henderson et al. 2011). Arylsulfonyl chloride $(10 \mathrm{mmol})$ was added in one portion to a solution of piperazine $(60 \mathrm{mmol})$ in $\mathrm{CH}_{2} \mathrm{Cl}_{2}$ at $0{ }^{\circ} \mathrm{C}$. The reaction mixture was stirred at $0{ }^{\circ} \mathrm{C}$ for $30 \mathrm{~min}$, diluted with $\mathrm{CH}_{2} \mathrm{Cl}_{2}$, quenched by the addition of saturated $\mathrm{NaHCO}_{3}$ (aq), washed with brine, and concentrated in vacuo to obtain the intermediate 3 .

\section{Synthesis of the target compounds $4 a-4 y$}

The synthetic route to the title compounds, the myricetin derivatives containing sulfonylpiperazine $(\mathbf{4 a}-\mathbf{4 y})$ are shown in Scheme 1. The intermediate $3(2.4 \mathrm{mmol})$ and potassium carbonate $(3.0 \mathrm{mmol})$ were stirred in $30 \mathrm{~mL}$ acetonitrile for $30 \mathrm{~min}$, then the intermediate $2(2.0 \mathrm{mmol})$ was added, the temperature was increased to $90{ }^{\circ} \mathrm{C}$ for $5 \mathrm{~h}$, the potassium carbonate was removed by filtration, and the acetonitrile was removed by spin evaporation. The target compounds $\mathbf{4 a}-\mathbf{4 y}$ were obtained by column chromatography (ethyl acetate:petroleum ether $=1: 2-2: 1$ ), with different yields. Their physical properties and spectral data are listed in the Supporting Information, and the ${ }^{1} \mathrm{H}$ NMR, ${ }^{13} \mathrm{C}$ NMR, ${ }^{19} \mathrm{~F}$ NMR and HRMS spectra attached in the Supporting Information.

\section{Results and discussion}

\section{Chemistry}

Twenty-five myricetin derivative containing sulfonylpiperazine were obtained in this study, all their structures were identified via ${ }^{1} \mathrm{H}$ NMR, ${ }^{13} \mathrm{C}$ NMR, ${ }^{19} \mathrm{~F}$ NMR and HRMS. The data of $4 \mathbf{a}$ was shown and discussed below. In the ${ }^{1} \mathrm{H}$ NMR spectrum, multiplet signals at $\delta 7.68-6.28 \mathrm{ppm}$ revealed the presence of aromatic nuclei, and a triplet peak at $\delta 3.91-3.94 \mathrm{ppm}$ indicated the presence of $\mathrm{O}-\mathrm{CH}_{2}-\mathrm{C}$ group. In addition, the high-frequency single peaks at $\delta 3.89-3.83 \mathrm{ppm}$ revealed the presence of five $-\mathrm{OCH}_{3}$. The nuclear magnetic signal at $\delta 2.93-2.38 \mathrm{ppm}$ revealed the presence of nuclear magnetic signal peak of piperazine's hydrogen proton. Finally, and three absorption signals at $\delta 2.28-1.40 \mathrm{ppm}$ indicated the presence of $\mathrm{C}-\mathrm{CH}_{2} \mathrm{CH}_{2} \mathrm{CH}_{2}-\mathrm{N}$ group. The absorption signals at $\delta 174.02$ and $72.12 \mathrm{ppm}$ in ${ }^{13} \mathrm{C}$ NMR spectra confirmed the presence of $-\mathrm{C}=\mathrm{O}$ and $-\mathrm{OCH}_{2}-$ groups, respectively. When fluorine is substituted on the benzene ring, carbon atoms attached to fluorine will migrate to the low field and the fluorine atom will split the two adjacent carbon atoms in ${ }^{13} \mathrm{C}$ NMR spectra. For example, compound $\mathbf{4 b}$ had an absorption peak at $\delta 163.99 \mathrm{ppm}$, which represented the nuclear magnetic peak of C-F. The absorption peak of the carbon atom at the same position in $\mathbf{4 a}$ was shown at $\delta 132.83 \mathrm{ppm}$. In addition, two adjacent carbon atoms of a carbon atom substituted by fluorine split into two adjacent absorption peaks at $\delta 116.42$ and $116.19 \mathrm{ppm}$. The 
two carbons at the same position in $\mathbf{4 a}$ showed a single absorption peak at $\delta 132.83 \mathrm{ppm}$. The high resolution mass spectrometry (HRMS) spectra of title compounds show characteristic absorption signals of $[\mathrm{M}+\mathrm{H}]^{+}$ions, which are consistent with their molecular weight.

\section{Antibacterial activity examination of the title compounds against Xoo, Xac and Rs in vitro}

The bacteriostatic activity of the compounds were measured by turbidimetric method (Zhong et al. 2017; Li et al. 2013), using Xac, Xoo and Rs as test strains, while using the commercial antibacterial agents bismerthiazol and thiodiazolecopper as control drugs. Some of the target compounds exhibited better antibacterial activities against Xac, Xoo and Rs in vitro at 100 and $50 \mu \mathrm{g} / \mathrm{mL}$, and the observed results would be shown in Table 1. For example, the myricetin has no obvious antibacterial activity, but most of the target compounds showed better antimicrobial activity than the lead compound myricetin. Compounds $\mathbf{4 a}, \mathbf{4 c}$ and $\mathbf{4 d}$ were exhibited favorable antibacterial activity against Xoo at $100 \mu \mathrm{g} / \mathrm{mL}$, with the inhibition rates of 72,77 and $75 \%$, which gained an advantage over that of bismerthiazol (55\%) and thiodiazole-copper (62\%). The inhibition rates of compounds $\mathbf{4 a}, \mathbf{4} \mathbf{c}$ and $\mathbf{4 d}$ against $\mathrm{Xoo}$ at $50 \mu \mathrm{g} / \mathrm{mL}$ were 52,53 and $43 \%$, which were better than that of bismerthiazol (39\%) and thiadiazole-copper (36\%). Similarly, compounds $\mathbf{4 h}$ and $\mathbf{4 p}$ showed higher antibacterial activity against Xac at $100 \mu \mathrm{g} / \mathrm{mL}$, the calculated inhibition of 74 and $87 \%$, which exceeded that of bismerthiazol (63\%) and thiodiazole-copper (51\%). Compounds $\mathbf{4 h}$ and $\mathbf{4 p}$ revealed superior antibacterial activities against Xac at $50 \mu \mathrm{g} / \mathrm{mL}$ with the inhibition rates of 42 and $41 \%$, respectively, which were also higher compared to bismerthiazol (19\%) and thiadiazole-copper
Table 1 Antibacterial activities of compounds $\mathbf{4 a}-\mathbf{4 y}$

\begin{tabular}{|c|c|c|c|c|c|c|}
\hline \multirow[t]{2}{*}{ Compounds } & \multicolumn{2}{|l|}{ Xoo } & \multicolumn{2}{|l|}{ Xac } & \multicolumn{2}{|l|}{ Rs } \\
\hline & $100 \mu \mathrm{g} / \mathrm{mL}$ & $50 \mu \mathrm{g} / \mathrm{mL}$ & $100 \mu \mathrm{g} / \mathrm{mL}$ & $50 \mu \mathrm{g} / \mathrm{mL}$ & $100 \mu \mathrm{g} / \mathrm{mL}$ & $50 \mu \mathrm{g} / \mathrm{mL}$ \\
\hline $4 a$ & $74 \pm 4$ & $52 \pm 4$ & $55 \pm 3$ & $31 \pm 2$ & $27 \pm 3$ & $25 \pm 2$ \\
\hline $4 b$ & $25 \pm 4$ & $24 \pm 1$ & $55 \pm 6$ & $27 \pm 1$ & $93 \pm 4$ & $66 \pm 3$ \\
\hline $4 c$ & $77 \pm 7$ & $53 \pm 2$ & $47 \pm 2$ & $33 \pm 0$ & $34 \pm 4$ & $10 \pm 4$ \\
\hline $4 d$ & $75 \pm 6$ & $43 \pm 5$ & $53 \pm 1$ & $36 \pm 2$ & $63 \pm 2$ & $51 \pm 5$ \\
\hline $4 e$ & $41 \pm 1$ & $26 \pm 1$ & $57 \pm 2$ & $31 \pm 3$ & $38 \pm 5$ & $28 \pm 2$ \\
\hline $4 f$ & $26 \pm 3$ & $20 \pm 2$ & $42 \pm 2$ & $33 \pm 2$ & - & - \\
\hline $4 g$ & $46 \pm 5$ & $33 \pm 3$ & $40 \pm 3$ & $39 \pm 2$ & $80 \pm 5$ & $39 \pm 3$ \\
\hline $4 h$ & $41 \pm 1$ & $33 \pm 5$ & $74 \pm 2$ & $42 \pm 1$ & - & - \\
\hline $4 i$ & $38 \pm 5$ & $33 \pm 5$ & $33 \pm 3$ & $11 \pm 5$ & $69 \pm 4$ & $51 \pm 3$ \\
\hline $4 j$ & $40 \pm 2$ & $36 \pm 2$ & $54 \pm 2$ & $40 \pm 3$ & $73 \pm 6$ & $39 \pm 1$ \\
\hline $4 k$ & $57 \pm 3$ & $25 \pm 6$ & $46 \pm 6$ & $23 \pm 4$ & $100 \pm 2$ & $96 \pm 5$ \\
\hline 41 & $24 \pm 2$ & $21 \pm 3$ & $55 \pm 3$ & $29 \pm 3$ & $68 \pm 1$ & $37 \pm 5$ \\
\hline $4 m$ & $28 \pm 5$ & $25 \pm 3$ & $26 \pm 3$ & $25 \pm 1$ & $100 \pm 3$ & $86 \pm 5$ \\
\hline $4 n$ & $22 \pm 2$ & $21 \pm 5$ & $48 \pm 1$ & $37 \pm 3$ & $48 \pm 2$ & $17 \pm 2$ \\
\hline 40 & $22 \pm 4$ & $13 \pm 2$ & $38 \pm 4$ & $23 \pm 2$ & $98 \pm 1$ & $90 \pm 3$ \\
\hline $4 p$ & $57 \pm 1$ & $29 \pm 6$ & $87 \pm 2$ & $41 \pm 1$ & $100 \pm 4$ & $90 \pm 2$ \\
\hline $4 q$ & $12 \pm 5$ & $7 \pm 1$ & $33 \pm 4$ & $28 \pm 1$ & $51 \pm 4$ & $19 \pm 2$ \\
\hline $4 r$ & $42 \pm 1$ & $19 \pm 7$ & $36 \pm 2$ & $33 \pm 3$ & $57 \pm 3$ & $55 \pm 1$ \\
\hline $4 s$ & $28 \pm 9$ & $3 \pm 3$ & $36 \pm 3$ & $26 \pm 2$ & $16 \pm 2$ & $10 \pm 1$ \\
\hline $4 t$ & $60 \pm 1$ & $7 \pm 0$ & $37 \pm 7$ & $16 \pm 4$ & $36 \pm 3$ & $29 \pm 3$ \\
\hline $4 u$ & $29 \pm 6$ & $17 \pm 5$ & $32 \pm 3$ & $26 \pm 3$ & $86 \pm 0$ & $80 \pm 3$ \\
\hline $4 v$ & $35 \pm 5$ & $5 \pm 2$ & $25 \pm 1$ & $26 \pm 3$ & $69 \pm 3$ & $30 \pm 5$ \\
\hline $4 w$ & $19 \pm 6$ & $8 \pm 6$ & $22 \pm 0$ & $11 \pm 4$ & $75 \pm 1$ & $73 \pm 3$ \\
\hline $4 x$ & $14 \pm 2$ & $9 \pm 4$ & $32 \pm 6$ & $17 \pm 2$ & $41 \pm 1$ & $22 \pm 6$ \\
\hline $4 y$ & $33 \pm 2$ & $15 \pm 2$ & $37 \pm 6$ & $26 \pm 7$ & $82 \pm 3$ & $77 \pm 3$ \\
\hline Myricetin & $11 \pm 4$ & $9 \pm 5$ & - & - & $21 \pm 2$ & $8 \pm 5$ \\
\hline $\mathbf{B T}^{\mathrm{b}}$ & $55 \pm 2$ & $39 \pm 2$ & $63 \pm 1$ & $19 \pm 6$ & $60 \pm 6$ & $52 \pm 0$ \\
\hline $\mathbf{T} \mathbf{C}^{\mathrm{b}}$ & $62 \pm 5$ & $36 \pm 4$ & $51 \pm 2$ & $19 \pm 2$ & $38 \pm 4$ & $21 \pm 2$ \\
\hline
\end{tabular}

Average of three replicates

$B T$ bismerthiazol, $T C$ thidiazole-copper

${ }^{\mathrm{b}}$ The commercial antibacterial agents bismerthiazol and thiodiazole-copper was used as positive control 
(19\%). In addition, compounds $4 \mathbf{b}, \mathbf{4 k}, \mathbf{4 m}, \mathbf{4 o}, \mathbf{4 p}, \mathbf{4 u}$ and 4y exhibited better antibacterial activities against Rs at 100 and $50 \mu \mathrm{g} / \mathrm{mL}$, with the inhibition rates of 93 and $66 \%, 100$ and 96\%, 100 and 86, 98 and 90\%, 100 and 90\%, 86 and $80 \%, 82$ and $77 \%$, respectively, which were over the control

Table $2 \mathrm{EC}_{50}$ values of some compounds against Xoo, Xac and Rs

\begin{tabular}{|c|c|c|c|c|}
\hline Tested & Compounds & Regression equation & $r$ & $\mathrm{EC}_{50}(\mu \mathrm{g} / \mathrm{mL})$ \\
\hline \multirow[t]{5}{*}{ Xoo } & $4 \mathbf{a}$ & $y=1.0037 x+3.4383$ & 0.9627 & 36 \\
\hline & $4 c$ & $y=1.3975 x+2.7873$ & 0.9754 & 38 \\
\hline & $4 d$ & $y=1.2546 x+2.9887$ & 0.9715 & 40 \\
\hline & $\mathbf{T C}^{\mathrm{a}}$ & $y=1.8570 x+1.5964$ & 0.9910 & 68 \\
\hline & $\mathbf{B T}^{\mathrm{a}}$ & $y=1.2079 x+2.6426$ & 0.9844 & 89 \\
\hline \multirow[t]{4}{*}{$\mathrm{Xac}$} & $4 h$ & $y=1.2056 x+2.7741$ & 0.9589 & 70 \\
\hline & $4 p$ & $y=2.0575 x+1.6741$ & 0.9550 & 41 \\
\hline & $\mathbf{T C}^{\mathrm{a}}$ & $y=1.2141 x+2.7624$ & 0.9752 & 70 \\
\hline & $\mathbf{B T}^{\mathrm{a}}$ & $y=1.1147 x+2.8064$ & 0.9878 & 93 \\
\hline \multirow[t]{14}{*}{ Rs } & $4 b$ & $y=2.3189 x+1.6664$ & 0.9921 & 27 \\
\hline & $4 d$ & $y=0.8746 x+3.9683$ & 0.9632 & 15 \\
\hline & $4 \mathbf{i}$ & $y=0.6887 x+3.9954$ & 0.9585 & 29 \\
\hline & $4 \mathbf{j}$ & $y=1.5022 x+2.8776$ & 0.9636 & 26 \\
\hline & $4 k$ & $y=1.8641 x+3.5488$ & 0.9507 & 6 \\
\hline & $4 m$ & $y=1.3204 x+4.2077$ & 0.9633 & 4 \\
\hline & 40 & $y=1.9801 x+3.0192$ & 0.9934 & 10 \\
\hline & $4 p$ & $y=1.3149 x+4.2120$ & 0.9617 & 4 \\
\hline & $4 r$ & $y=0.6145 x+4.1342$ & 0.9938 & 26 \\
\hline & $4 \mathbf{u}$ & $y=0.8169 x+4.2210$ & 0.9904 & 5 \\
\hline & $4 w$ & $y=1.3517 x+3.1764$ & 0.9582 & 22 \\
\hline & $4 y$ & $y=1.0833+4.2902$ & 0.9604 & 5 \\
\hline & $\mathbf{T C}^{\mathrm{a}}$ & $y=0.6931 x+3.4289$ & 0.9773 & 185 \\
\hline & $\mathbf{B T}^{\mathrm{a}}$ & $y=0.8701 x+4.0372$ & 0.9747 & 13 \\
\hline
\end{tabular}

Average of three replicates

$B T$ bismerthiazol, $T C$ thidiazole-copper

${ }^{a}$ The commercial antibacterial agents bismerthiazol and thidiazolecopper was used as positive control
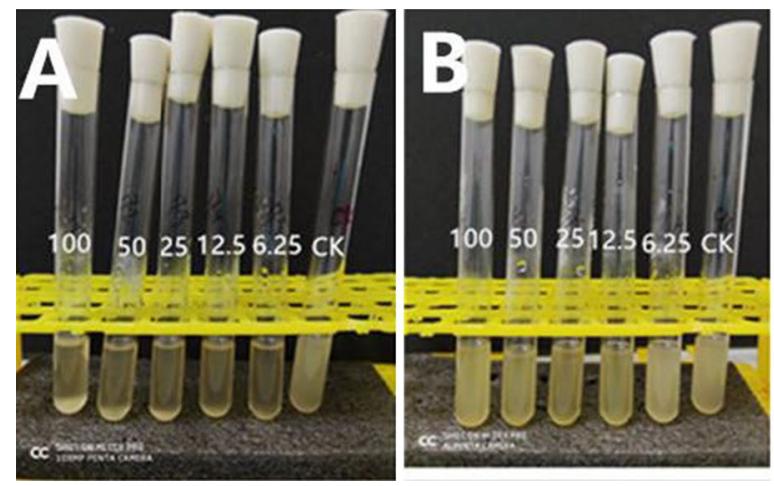

agents bismerthiazol (60 and 52\%) and thiodiazole-copper (38 and 20\%).

According to the preliminary screening results of antibacterial activity, $\mathrm{EC}_{50}$ values of some of the compounds showed excellent antibacterial activities against Xoo, Xac and Rs, as shown in Table 2. We can know from Table 2, the compounds $4 \mathbf{a}, \mathbf{4 c}$ and $\mathbf{4 d}$ exerted distinct activity against Xoo with the $\mathrm{EC}_{50}$ values were 36,38 and $40 \mu \mathrm{g} / \mathrm{mL}$, respectively, which preceded that of bismerthiazol $(89 \mu \mathrm{g} / \mathrm{mL})$ and thiodiazole-copper $(68 \mu \mathrm{g} / \mathrm{mL})$. Compound $\mathbf{4 p}$ revealed preferable antibacterial activity against Xac with $\mathrm{EC}_{50}$ values of $41 \mu \mathrm{g} / \mathrm{mL}$, which was superior to bismerthiazol $(93 \mu \mathrm{g} / \mathrm{mL})$ and thiodiazole-copper ( $70 \mu \mathrm{g} / \mathrm{mL})$. Compounds $\mathbf{4 k}, \mathbf{4 m}, \mathbf{4 o}$, $\mathbf{4 p}, \mathbf{4 u}$ and $\mathbf{4 y}$ against $\mathrm{Rs}$ with $\mathrm{EC}_{50}$ values of $6,4,10,4,5$ and $5 \mu \mathrm{g} / \mathrm{mL}$, respectively, which prevailed over that of bismerthiazol $(13 \mu \mathrm{g} / \mathrm{mL})$ and thiodiazole-copper $(185 \mu \mathrm{g} / \mathrm{mL})$ signally. We can clearly observe the difference in activity against Rs between compound $\mathbf{4 p}$, myricetin, control drugs bismerthiazol and thiodiazole-copper in Fig. 2.

\section{Structure-activity relationship analysis of antibacterial activities}

Table 1 revealed that the antibacterial activities of the title compounds were considerably affected by the length of the carbon chain and different substituents on sulfonyl groups. For instance, When $n=3$ and $\mathrm{R}$ were substituted with phenyl, 4- $\mathrm{CH}_{3}-\mathrm{Ph}, 4-\mathrm{NO}_{2}-\mathrm{Ph}$, thienyl or $2-\mathrm{NO}_{2}-\mathrm{Ph}$, these compounds exhibited significant Rs inhibitory activity with the inhibition rates of $100,98,100$ and $82 \%$ at $100 \mu \mathrm{g} / \mathrm{mL}$, respectively, which were better than the compounds with $n=4$ on the same substituent group with the inhibition rates of $27,34,63$ and $68 \%$. When $n=4$ and $\mathrm{R}$ were substituted with 4-F-Ph or pyridyl, these compounds performed better Rs inhibitory activity with the inhibition rates of 93 and $100 \%$ at $100 \mu \mathrm{g} / \mathrm{mL}$, which were exceeded than the compounds with $n=3$ on the same substituent group with the

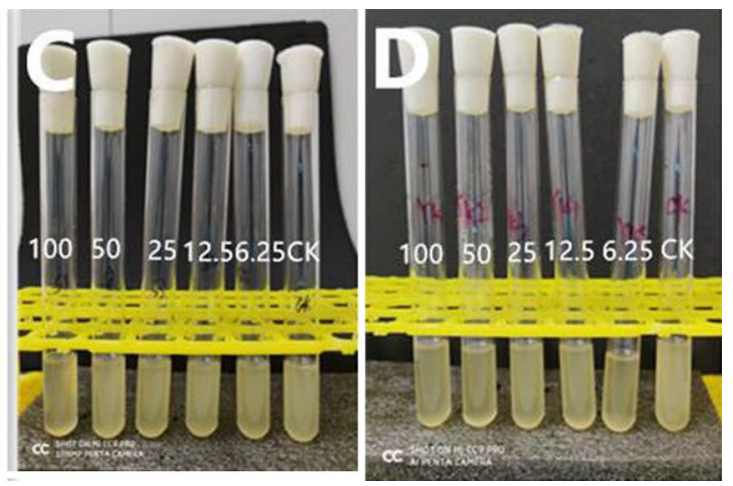

Fig. 2 Antibacterial activities of compound $\mathbf{4 p}$ (a), myricetin (b), thiodiazole-copper (c) and bismerthiazol (d) against Rs test in vitro at 100, 50, $25,12.5$ and $6.25 \mu \mathrm{g} / \mathrm{mL}$ 

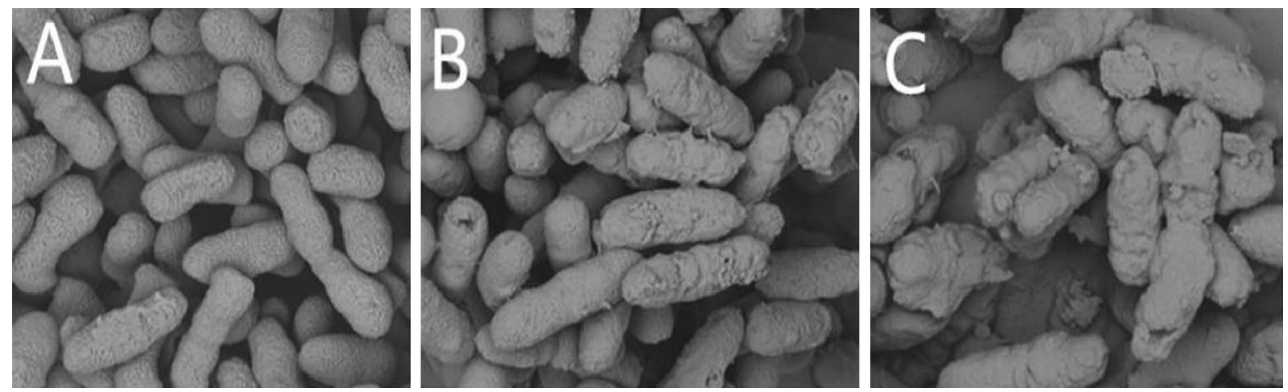

Fig. 3 SEM images for Rs after incubated in different concentration of compound $\mathbf{4 p}$. a $0 \mathrm{mg} / \mathrm{mL}, \mathbf{b} 50 \mu \mathrm{g} / \mathrm{mL}$ and $\mathbf{c} 100 \mu \mathrm{g} / \mathrm{mL}$. Scale bar for a-c are $2 \mu \mathrm{m}$

inhibition rates of 48 and $41 \%$. When $\mathrm{R}$ was substituted with 4- $\mathrm{NO}_{2}-\mathrm{Ph}$, compounds $\mathbf{4 d}$ and $\mathbf{4 p}$ showed certain inhibitory activity against Xoo, Xac and Rs at $100 \mu \mathrm{g} / \mathrm{mL}$. The inhibitory activity of compound $\mathbf{4 d}$ against Xoo is better when $n=4$. Similarly, the inhibitory activity of compound 4p against Xac and Rs is best when $n=3$. Compared with the previous work of research group, this article introduced sulfonylpiperazine to the structure of myricetin, and some compounds show better inhibitory activity against Rs with $\mathrm{EC}_{50}$ values between 4 and $10 \mu \mathrm{g} / \mathrm{mL}$, which is superior to the myricetin derivatives containing thiadiazole sulfide with $\mathrm{EC}_{50}$ values between 28 and $39 \mu \mathrm{g} / \mathrm{mL}$ (Ruan et al. 2018a, b). And the antibacterial activity of these compounds were verified by SEM.

\section{Scanning electron microscopy (SEM) studies}

To further explore the mechanism of antibacterial action against Rs, scanning electron microscopy (SEM) studies were carried out using the designated compound $\mathbf{4 p}$ and the observed SEM micrographs are shown in Fig. 3. Obviously, when there is no drug action, the form of the strain is plump and short and thick. However, the surface of the bacteria began to appear wrinkle at $50 \mu \mathrm{g} / \mathrm{mL}$, which became more pronounced as the concentration of the drug increased to $100 \mu \mathrm{g} / \mathrm{mL}$. It was obtained by SEM, the bacteriostatic mechanism of compound $\mathbf{4 p}$ is to act on the surface of bacteria by drugs, thus causing the bacteria to fold and shrink, resulting in incomplete bacterial structure, so as to achieve the goal of bacteriostasis.

\section{Conclusion}

In summary, 25 myricetin derivatives containing sulfonylpiperazine were designed and synthesized. And test their in vitro activity on the three strains Xoo, Xac and Rs. Some compounds showed excellent inhibitory activity against Rs with $\mathrm{EC}_{50}$ values between 4 and $10 \mu \mathrm{g} / \mathrm{mL}$. Among them, compound $\mathbf{4 p}$ against $\mathrm{Xac}$ and $\mathrm{Rs}$ with $\mathrm{EC}_{50}$ value of 41 and $4 \mu \mathrm{g} / \mathrm{mL}$, which far exceeded that of bismerthiazol (93 and $13 \mu \mathrm{g} / \mathrm{mL}$, respectively) and thiodiazole-copper (67 and $185 \mu \mathrm{g} / \mathrm{mL})$, respectively. Meanwhile, the inhibitory rate of compound $\mathbf{4 p}$ on Xoo is $57 \%$ at $100 \mu \mathrm{g} / \mathrm{mL}$, which was slightly better than the control drug bismerthiazol $(55 \mu \mathrm{g} /$ $\mathrm{mL}$ ). Meanwhile, compound $\mathbf{4 m}$ against $\mathrm{Rs}$ with $\mathrm{EC}_{50}$ value of $4 \mu \mathrm{g} / \mathrm{mL}$, which better than the control drug bismerthiazol $(13 \mu \mathrm{g} / \mathrm{mL})$ and thiodiazole-copper $(185 \mu \mathrm{g} / \mathrm{mL})$. Scanning electron microscopy analysis further confirmed that the title compounds caused the bacteria to shrink by acting on the surface of the bacteria, so as to achieve antibacterial effect. Therefore, the designed compounds can be used as potential antibacterial drugs for further research to find new antibacterial drugs.

Acknowledgements The authors gratefully acknowledge the financial support of the National Key Research and Development Program of China (No. 2017YFD0200506), the National Nature Science Foundation of China (No. 21867003) and Science Fundof Guizhou, China (Nos. 20191105, 20192452).

Open Access This article is licensed under a Creative Commons Attribution 4.0 International License, which permits use, sharing, adaptation, distribution and reproduction in any medium or format, as long as you give appropriate credit to the original author(s) and the source, provide a link to the Creative Commons licence, and indicate if changes were made. The images or other third party material in this article are included in the article's Creative Commons licence, unless indicated otherwise in a credit line to the material. If material is not included in the article's Creative Commons licence and your intended use is not permitted by statutory regulation or exceeds the permitted use, you will need to obtain permission directly from the copyright holder. To view a copy of this licence, visit http://creativecommons.org/licenses/by/4.0/.

\section{References}

Alina C, Federica F, Andreina B et al (2020) Optimization of 2-(1H-imidazo-2-yl)piperazines series of trypanosoma brucei growth inhibitors as potential treatment for the second stage of HAT. Bioorg Med Chem Lett. https://doi.org/10.1016/j. bmcl.2020.127207 
Chen W, Li YX, Li YH et al (2018) Design, synthesis and biological activity of 2-cyanophenylsulfonylurea derivatives. Chin J Org Chem 38:2747-2775. https://doi.org/10.6023/cjoc201804019

Chen Y, Li P, Su SJ et al (2019) Synthesis and antibacterial and antiviral activities of myricetin derivatives containing a 1,2,4-triazole Schiff base. RSC Adv 9:23045-23052. https://doi.org/10.1039/ c9ra05139b

Fu YX, Wang YH, Tong XS et al (2019) EDACO, a derivative of myricetin, inhibits the differentiation of Gaoyou duck embryonic osteoclasts in vitro. Br Poult Sci 60:169-175. https://doi. org/10.1080/00071668.2018.1564239

Guitard R, Paul JF, Nardello-Rataj V et al (2016) Myricetin, rosmarinic and carnosic acids as superior natural antioxidant alternatives to alpha-tocopherol for the preservation of omega-3 oils. Food Chem 213:284-295. https://doi.org/10.1016/j.foodchem.2016.06.038

Henderson BJ, Carper DJ, González C et al (2011) Structure-activity relationship studies of sulfonylpiperazine analogues as novel negative allosteric modulators of human neuronal nicotinic receptors. J Med Chem 54:8681-8692. https://doi.org/10.1021/jm201294r

Jalili-Baleh L, Babaei E, Abdpour S et al (2018) A review on flavonoid-based scaffolds as multi-target-directed ligands (MTDLs) for Alzheimer's disease. Eur J Med Chem 152:570-589. https://doi. org/10.1016/j.ejmech.2018.05.004

Jiang SC, Su SJ, Chen M et al (2020a) Antibacterial activities of novel dithiocarbamate-containing $4 \mathrm{H}$-chromen-4-one derivatives. J Agric Food Chem 68:5641-5647. https://doi.org/10.1021/acs. jafc.0c01652

Jiang SC, Tang X, Chen M et al (2020b) Design, synthesis and antibacterial activities against Xanthomonas oryzae pv. oryzae, Xanthomonas axonopodis pv. Citri and Ralstonia solanacearum of novel myricetin derivatives containing sulfonamide moiety. Pest Manag Sci 76:853-860. https://doi.org/10.1002/ps.5587

Khatoon UT, Rao GVSN, Mohan KM et al (2017) Antibacterial and antifungal activity of silver nanospheres synthesized by tri-sodium citrate assisted chemical approach. Vacuum 146:259-265. https:// doi.org/10.1016/j.vacuum.2017.10.003

Khatoon UT, Rao GVSN, Mohan MK et al (2018) Comparative study of antifungal activity of silver and gold nanoparticles synthesized by facile chemical approach. J Environ Chem Eng 6:5837-5844. https://doi.org/10.1016/j.jece.2018.08.009

Li P, Yin J, Xu W et al (2013) Synthesis, antibacterial activities and 3D-QSAR of sulfone derivatives containing 1, 3, 4-oxadiazole moiety. Chem Biol Drug Des 82:546-556. https://doi.org/10.1111/ cbdd. 12181

Li P, Tian P, Chen Y et al (2017) Novel bisthioether derivatives containing a 1,3,4-oxadiazole moiety: design, synthesis, antibacterial and nematocidal activities. Pest Manag Sci 74:844-852. https:// doi.org/10.1002/ps.4762

Li P, Chen Y, Xia RJ et al (2019) Synthesis and biological activities of myricetin derivatives containing quinoxaline. Chem J Chin Univ 40:909-917. https://doi.org/10.7503/cjcu20180828

Manthey JA, Guthrie N (2002) Antiproliferative activities of citrus flavonoids against six human cancer cell lines. J Agric Food Chem 50:5837-5843. https://doi.org/10.1021/jf020121d

Mo F, Ma J, Yang X (2020) In vitro and in vivo effects of the combination of myricetin and miconazole nitrate incorporated to thermosensitive hydrogels, on C. albicans biofilms. Phytomedicine. https ://doi.org/10.1016/j.phymed.2020.153223

Nadia HM, Mona SM (2020) New imidazolone derivatives comprising a benzoate or sulfonamide moiety as anti-inflammatory and antibacterial inhibitors: design, synthesis, selective COX-2, DHFR and molecular-modeling study. Bioorg Chem. https://doi. org/10.1016/j.bioorg.2019.103438

Pasetto S, Pardi V, Murata RM (2014) Anti-HIV-1 activity of flavonoid myricetin on HIV-1 infection in a dual-chamber in vitro model. PLoS ONE 9:e115323. https://doi.org/10.1371/journ al.pone. 0115323

Peng Z, Wang MH (2018) Design, synthesis and biological activity of novel fluorinated pyridine piperazine derivatives. Pesticide 57:641-644

Ruan XH, Zhang C, Jiang SC et al (2018a) Design, synthesis, and biological activity of novel myricetin derivatives containing amide, thioether, and 1,3,4-thiadiazole moieties. Molecules 23:3132. https://doi.org/10.3390/molecules23123132

Ruan XH, Zhao HJ, Zhang C et al (2018b) Syntheses and bioactivities of myricetin derivatives containing piperazine acidamide moiety. Chem J Chin Univ 39:1197-1204. https://doi.org/10.7503/cjcu20170740

Soliman AM, Karam HM, Mekkawy MH et al (2020) Antioxidant activity of novel quinazolinones bearing sulfonamide: potential radiomodulatory effects on liver tissues via $\mathrm{NF}-\kappa \mathrm{B} / \mathrm{PON} 1$ pathway. Eur J Med Chem. https://doi.org/10.1016/j.ejmec h.2020.112333

Štěpánková J, Kugler M, Holub J et al (2020) Sulfonamido carboranes as highly selective inhibitors of cancer-specific carbonic anhydrase IX. Eur J Med Chem. https://doi.org/10.1016/j.ejmec h. 2020.112460

Suleman H, Maulud AS, Syalsabila A et al (2020) High-pressure experimental and theoretical study of $\mathrm{CO}_{2}$ solubility in aqueous blends of lysine salts with piperazine as new absorbents. Fluid Phase Equilib 507:112429. https://doi.org/10.1016/j.fluid.2019.112429

Sun F, Zheng XY, Ye J et al (2012) Potential anticancer activity of myricetin in human T24 bladder cancer cells both in vitro and in vivo. Nutr Cancer 64:599-606. https://doi.org/10.1080/01635 581.2012.665564

Tang X, Zhang C, Chen M et al (2020) Synthesis and antiviral activity of novel myricetin derivatives containing a ferulic acid amide scaffolds. New J Chem 44:2374-2379. https://doi.org/10.1039/c9nj05867b

Wang S, Tong Y, Lu S et al (2010) Anti-inflammatory activity of myricetin isolated from myrica rubraSieb. et Zucc. Leaves Planta Med 76:1492-1496. https://doi.org/10.1055/s-0030-1249780

Xu J, Wei MX, Li MG et al (2015) Synthesis and anti-cancer activity of new artemisinone sulfone-piperazine-sulfonamide derivatives. Chem J Chin Univ 36:919-926. https://doi.org/10.7503/ cjcu20140906

Xue W, Song BA, Zhao HJ et al (2015) Novel myricetin derivatives: design, synthesis and anticancer activity. Eur J Med Chem 97:155-163. https://doi.org/10.1016/j.ejmech.2015.04.063

Yan BR, Lv XY, Du H et al (2016) Synthesis and biological activities of novel quinazolinone derivatives containing a 1,2,4-triazolylthioether moiety. Chem Pap 70:983-993. https://doi.org/10.1515/ chempap-2016-0034

Yu MS, Lee J, Lee JM et al (2012) Identification of myricetin and scutellarein as novel chemical inhibitors of the SARS coronavirus helicase, nsP13. Bioorg Med Chem Lett 22:4049-4054. https:// doi.org/10.1016/j.bmcl.2012.04.081

Zhang C, Jiang SC, Chen Y et al (2019) Synthesis and biological of novel myricetin derivatives containing 1,3,4-oxadiazoles. Chin J Org Chem 39:1160-1168. https://doi.org/10.6023/cjoc201809040

Zhang D, Jiang X, Xiao L et al (2020) Mechanistic studies of inhibition on acrolein by myricetin. Food Chem. https://doi.org/10.1016/j. foodchem.2020.126788

Zhong XM, Wang XB, Chen LJ et al (2017) Synthesis and biological activity of myricetin derivatives containing 1,3,4-thiadiazole scaffold. Chem Cent J 11:106. https://doi.org/10.1186/s1306 5-017-0336-7

Zou LF, Li YR, Chen GY (2011) A non-marker mutagenesis strategy to generate poly-hrp gene mutants in the rice pathogen Xanthomonas oryzae pv. oryzicola. Agric Sci China 10:1139-1150

Publisher's Note Springer Nature remains neutral with regard to jurisdictional claims in published maps and institutional affiliations. 